\title{
Innovation toward the Reinvigoration of the Plant Extracts Industry in Developing Countries
}

\author{
Rosemarie Skeene $^{1}$, Sharad Maharaj ${ }^{2 *} \oplus$, David R. McGaw ${ }^{2}$, Dara M. Farrell ${ }^{2}$ \\ ${ }^{I}$ School of Engineering, Technology and Architecture, North Campus, Miami Dade College, Miami, FL 11380, United States \\ ${ }^{2}$ Department of Chemical Engineering, The University of the West Indies, St. Augustine, Trinidad and Tobago
}

Received 16 June 2021; Revised 23 August 2021; Accepted 28 August 2021; Published 01 September 2021

\begin{abstract}
Smaller countries with economies that are fossil fuel based face the challenge of diversifying their economies, with an ideal emphasis on clean technologies. In this case study approach, we undertook a techno-feasibility study to evaluate the potential for constructing and operating a supercritical fluid extraction plant in Trinidad and Tobago to produce the oils and oleoresins of turmeric. This approach was based on the premise of the importance of data derived from laboratoryscale analysis for informing commercialization decisions. In our case, the laboratory study identified that the optimal extraction approach was an innovative two-stage extraction technique $\left(25^{\circ} \mathrm{C}\right.$ and 65 bar for 60 minutes, followed by 50 ${ }^{\circ} \mathrm{C}$ and 350 bar for a further 120 minutes). This optimal method had a conservatively projected extraction yield of $7 \%$. We then evaluated a commercial operation guided by the laboratory study. Our calculations showed an internal rate of return of $19 \%$ with a net present value of US $\$ 1.878$ million over a period of 10 years at a discount rate of $10 \%$. Based on our results, we conclude that this project may be a viable avenue for the sustainable development of Trinidad and Tobago and could be further explored.
\end{abstract}

Keywords: Supercritical Fluid Extraction; Diversification; Turmeric; Techno-Economic Study.

\section{Introduction}

Many plant species in the tropics secrete complex chemicals that can be extracted and incorporated into various consumer products. They can be found in food flavourings, aromatherapy/personal care products, nutraceuticals / pharmaceuticals, perfumes, and a variety of other products (such as security sprays, insecticides, dyes, and coloring). There are two types of plant extracts: essential oils and oleoresins. Essential oils [1-3] are the volatile oils that produce plant odors. However, oleoresins [4], often called fixed oils, have much higher vapor pressures than essential oils and melt at higher temperatures. Several market research companies have evaluated the current and projected global essential oil markets [4-8]. There is reasonable agreement between these authors' assessments, which indicate that global market sales were $\$ 7.0$ billion to $\$ 8.0$ billion in 2018 ; the authors expected the market to further increase, giving rise to a compound annual growth rate (CAGR) of between $8.7 \%$ and $9.7 \%$ over the period 2019 to 2026 . This suggests a projected doubling of market size to approximately $\$ 15.6$ billion from 2019 to 2026 . There are similar positive forecasts for the oleoresin market. According to Marketsandmarkets [9], the estimated value of the global oleoresins market was US\$1.2 billion in 2019 and is projected to reach US $\$ 1.7$ billion by 2025, recording a CAGR of $6.0 \%$ from 2019 to 2025 .

\footnotetext{
* Corresponding author: sharad.maharaj@sta.uwi.edu

$>$ This is an open access article under the CC-BY license (https://creativecommons.org/licenses/by/4.0/).

(c) Authors retain all copyrights. 
The Caribbean has a long history of producing essential oils, although the range of products has been somewhat limited. Bay oil has been produced in Dominica since the 19th century [10] and lime oil was produced by several islands for many decades. Recent oil production endeavours have included pimento oil in Jamaica [11], nutmeg oil in Grenada [12], anise oil in Trinidad [13], and bay oil in Tobago [14]. These attempts have met with varying levels of success. Anise oil was produced by the Pernod Company in Trinidad and Tobago on lands that were formerly sugarcane estates; however, production was recently halted. In addition, a bay oil facility was installed in Tobago in the 1970s to exploit a mature bay tree plantation but was not operated continuously. Although their industries are small by international standards, essential oil production has made significant contributions to the economies of the small islands of Dominica and Grenada $[12,14]$.

It is proposed that the plant extracts industry be re-established as part of the diversification of the economy of Trinidad and Tobago to reduce its dependence on oil and natural gas. This requires evaluations of the potential for constructing and operating appropriate extraction technologies for the manufacture of viable commercial extracts from indigenous plants. There are a wide variety of local plants, some of which have already been studied, such as Ylang Ylang flowers [15], jasmine flowers [16], hot peppers [17], and basil [18]. However, turmeric is another viable option for commercial extract production, since its use as a pharmaceutical and a food flavouring $[19,20]$ has been established globally, and it contains both essential oils and an oleoresin. The major constituent of the oleoresin is curcumin, which has shown promise as a pharmaceutical in the treatment of cancer and arthritis [21, 22]. Turmeric is grown commercially in Trinidad, but it is consumed directly as a food flavouring and is not further processed to create value-added products.

This paper presents an evaluation of the economic potential of the production and export of turmeric extract in Trinidad and Tobago as a new avenue toward diversification of the twin-island nation's economy. We evaluated existing processes and then undertook an extensive experimental program to study the extraction of the essential oil and the oleoresin from indigenous turmeric using the most viable process. The experimental program was designed to identify the optimal processing conditions as an input for a subsequent economic evaluation of the project's commercial potential.

\subsection{Choice of Process}

Separate technologies have traditionally been required to extract essential oils and oleoresins. The extraction of essential oils typically utilized steam or boiling water to vaporize the oil, and the most common technique used was steam distillation extraction (SDE) [23-25]. In SDE, steam is passed through a bed containing the plant material to vaporize the oil, the oil/steam mixture is subsequently condensed, and the oil is separated from the mixture by virtue of the immiscibility of the oil and the water. However, oleoresins are not volatile, so they cannot be separated from the plant materials using steam distillation. They have typically been extracted by solvent extraction [24, 25]. In this procedure a suitable liquid solvent is used to dissolve the oleoresin but not the matrix of the plant material. The oil is subsequently separated from the oil/water mixture by fractionation.

However, in the last two decades of the 20th century, the concept of supercritical fluid extraction (SFE) has been promoted as a viable and more flexible alternative to both steam distillation and solvent extraction [26-28]. The extraction is effected by passing carbon dioxide at high pressure and just above room temperature $\left(28^{\circ} \mathrm{C}\right.$ in this context) through a packed bed of the plant material connected to the extractors. The essential oil/oleoresin dissolves in the supercritical carbon dioxide and passes to one of the separators where the pressure is reduced to release the extract. The carbon dioxide is then compressed, raising it to the extraction pressure, and it is then recycled back through the extractor. SFE offers several advantages over traditional technologies: it ensures that there is no solvent contamination of the product; it operates at close to ambient temperature, so that the composition of the final extract is close to that of the extractable material in the plant matrix; and its flexible operation enables the extraction of both essential oils and oleoresins using the same equipment. As a result of our review of the available technologies, SFE using carbon dioxide was identified as the most suitable extraction process because of the flexibility of the technique; this is especially useful in the case of turmeric, which has both an essential oil and an oleoresin. Furthermore, carbon dioxide is readily available as a raw material from the ammonia plants at the Point Lisas Industrial Estate in Trinidad.

The remainder of this paper is organized as follows: Section 2 provides details about the experimental study, and Section 3 presents typical results from the series of experiments. These laboratory results were used to guide the selection of operating conditions for a commercial operation, and this discussion is presented in Section 4. The rationale for this choice is discussed in Section 4.1, and the details of the subsequent financial analysis follow in Section 4.2. Our conclusions are presented in Section 5.

\section{Experimental Study}

\subsection{Objective of the Experimental Program}

The objective of the experimental program was to identify the optimal operating conditions for the extraction of the essential oil and oleoresin from local turmeric using carbon dioxide. These conditions would then be used to determine whether such a process would be commercially feasible in Trinidad. 


\subsection{Raw Material Supply and Preparation}

Turmeric was supplied by a commercial farmer in South Trinidad. It was oven dried to approximately $4 \%$ wet basis (w.b.) and milled to $<0.85 \mathrm{~mm}$ before use.

\subsection{Experimental Procedure}

Laboratory extractions were carried out on an Applied Separations Spe-ed SFE unit (Applied Separations, Allentown, PA, USA-Spe-ed SFE, model 7011) using a $100 \mathrm{ml}$ vessel with carbon dioxide as the extracting solvent. Approximately 20 to $25 \mathrm{~g}$ of dried, milled turmeric were charged to the vessel for each experiment. The critical point for carbon dioxide is at $31.1^{\circ} \mathrm{C}$ and a pressure of 73.8 bar. The experimental program covered the following processing conditions:

- Subcritical extraction-over a temperature range of 25 to $30^{\circ} \mathrm{C}$ and a range of pressure of 65 bar to 71 bar.

- Supercritical extraction-conducted using pressures ranging from 100 bar to 350 bar and temperatures ranging from 35 to $60{ }^{\circ} \mathrm{C}$.

- Combined extraction-extraction under subcritical conditions followed by extraction under supercritical conditions $\left(25^{\circ} \mathrm{C}\right.$ and 65 bar pressure for 1 hour and then operating at 50 bar and 350 bar pressure).

The criteria used to select the most appropriate operating conditions for commercial operation were percentage yield and product quality, as demonstrated by the composition of the extract. Extract composition was measured by gas chromatography-mass spectrometry (GC-MS; Agilent Technolgies, Santa Clara, CA, USA-6890N, 5973 inert, respectively) for essential oils, and the curcumin content of the oleoresin was measured using a UV/Vis spectrophotometer (Thermo Fisher Scientific, Waltham, Massachusetts, USA-Spectronic Helios Alpha).

\section{Experimental Results}

\subsection{Subcritical Extraction Results}

Figure 1 shows a typical set of extraction curves for the experiments carried out under subcritical conditions. The plot shows that the final overall yields range between 8 and $9 \%$ of the raw material mass, and the bulk of the extraction occurs in the first three hours.

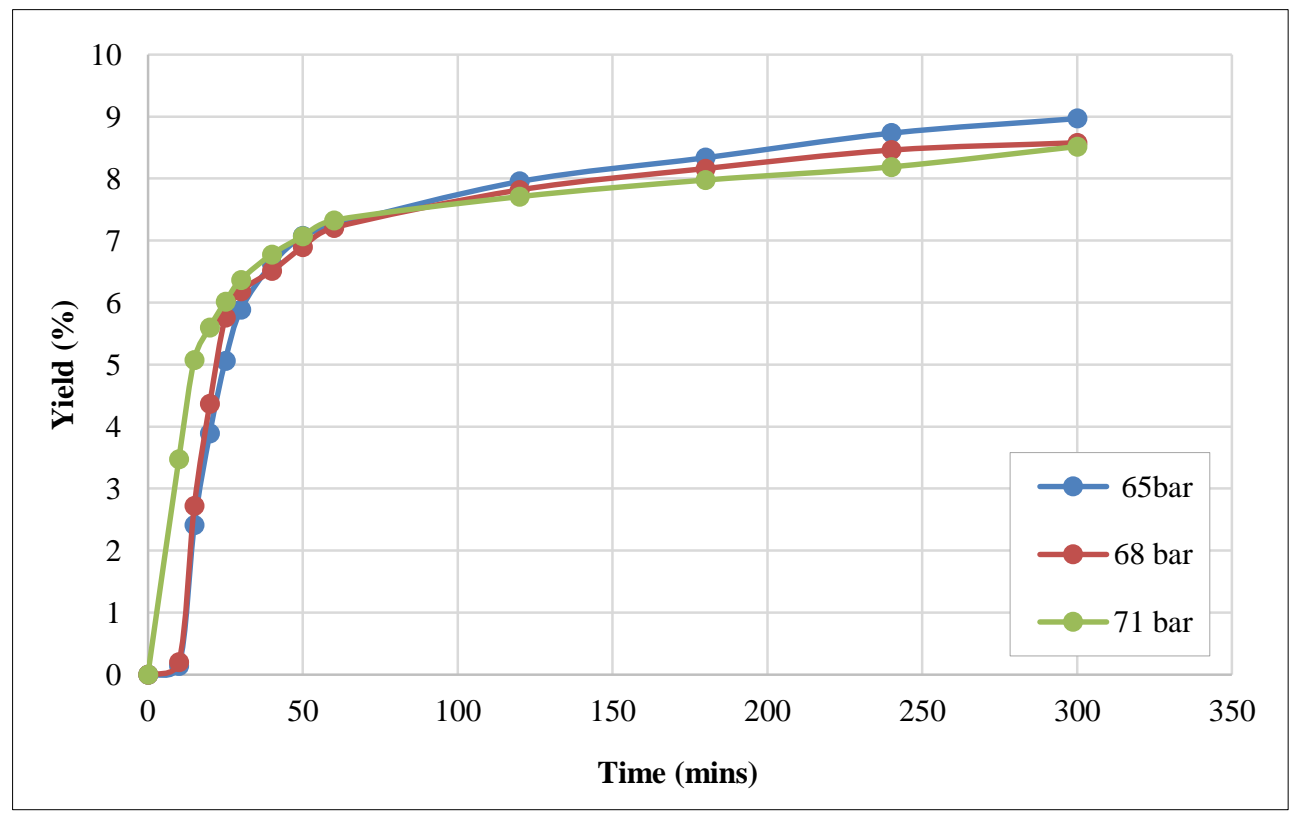

Figure 1. Subcritical extraction curves at $25^{\circ} \mathrm{C}$ at varying pressures

Figure 2 shows typical results for the extraction of the individual components. No oleoresin was detected. 


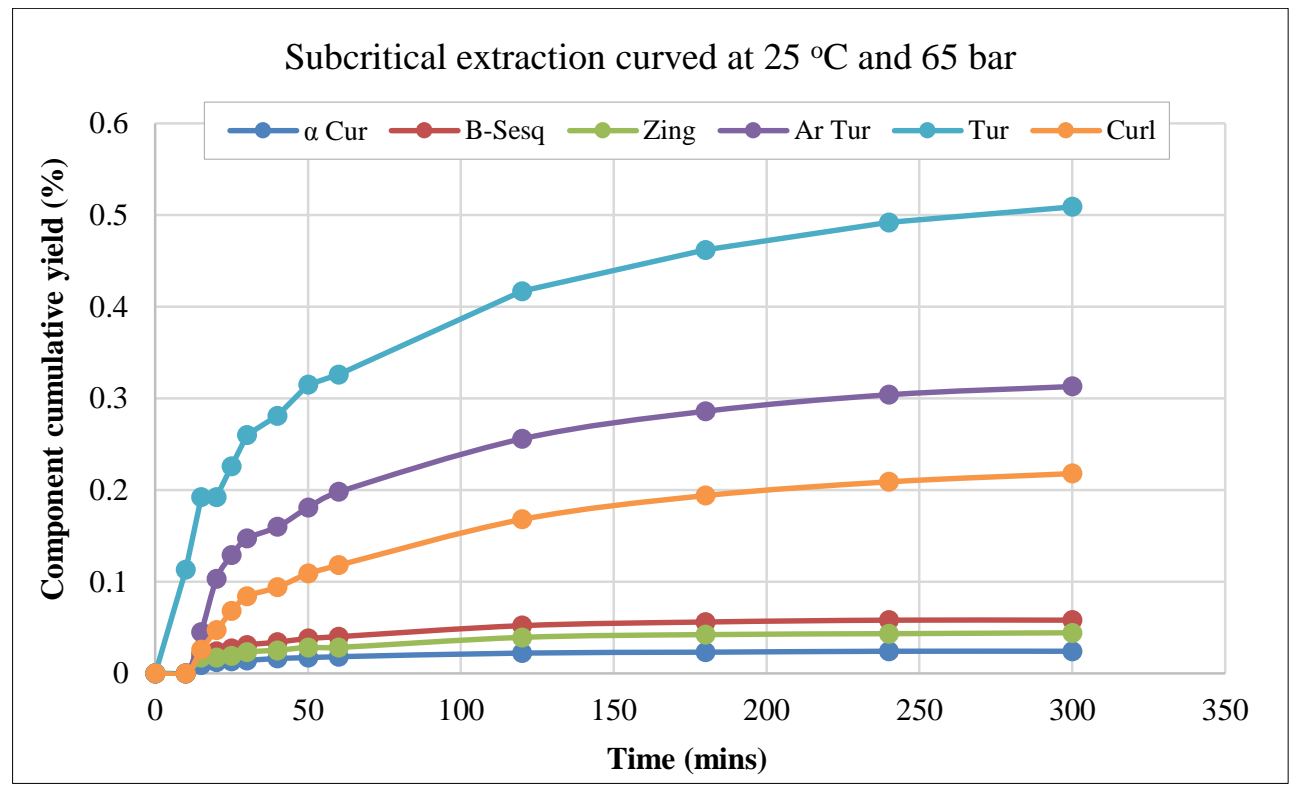

Figure 2. Extraction of individual components during subcritical extraction

\subsection{Supercritical Extraction Results}

A typical set of supercritical extraction results is shown in Figure 3. The plot shows that the final overall yields range between 7 and $>11 \%$, and the highest yield is obtained at a pressure of 200 bar. Most of the extraction takes place within the first two hours.

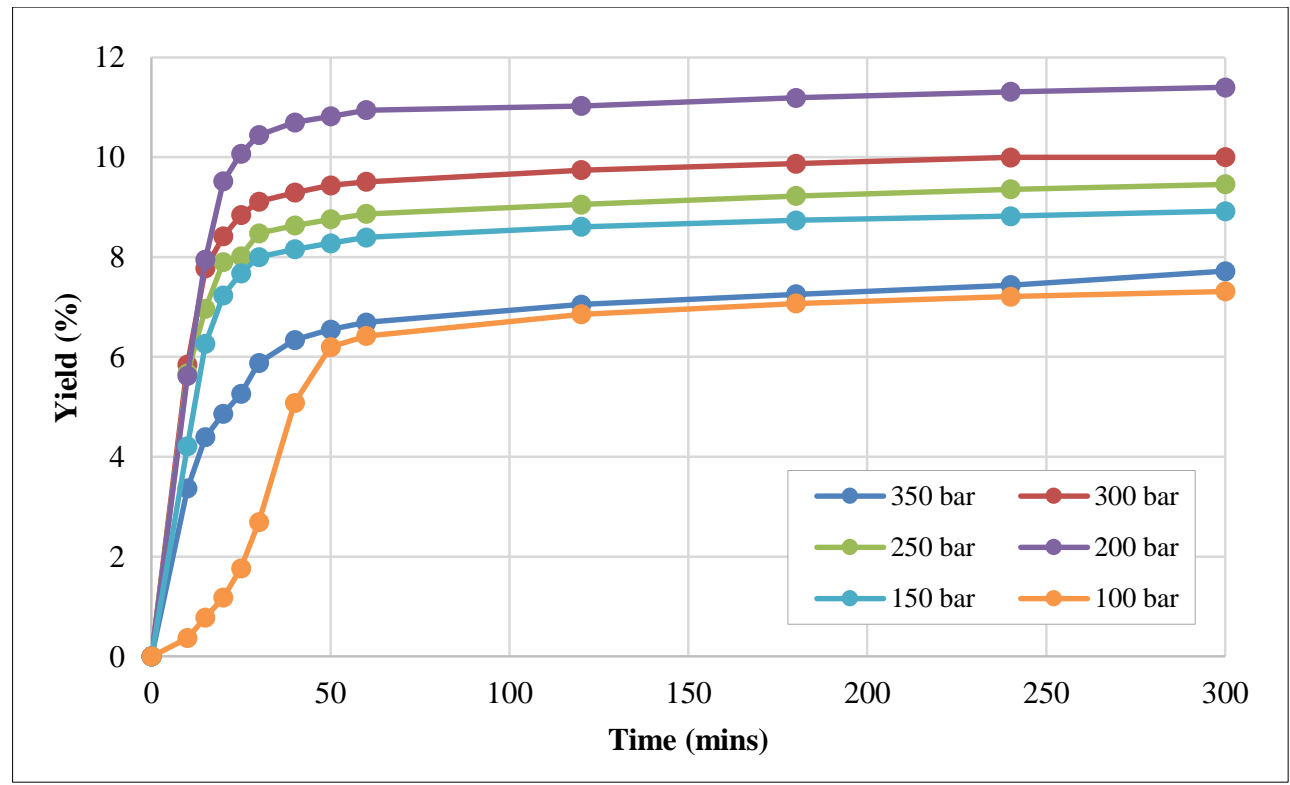

Figure 3. Extraction curve at $45^{\circ} \mathrm{C}$

In this case, the extract contained all the essential oil as well as the bulk of the oleoresin content. The curcumin content of the extract was measured as $2.79 \times 10^{-3} \mathrm{~g} / \mathrm{ml}, 4.00 \times 10^{-3} \mathrm{~g} / \mathrm{ml}$, and $2.07 \times 10^{-2} \mathrm{~g} / \mathrm{ml}$ at pressures of 250 bar, $300 \mathrm{bar}$, and $350 \mathrm{bar}$, respectively. Thus, although operating at higher pressures does not produce the maximum extract yield, it does provide a significantly higher curcumin content, and hence better quality.

\subsection{Combined Mode Extraction}

Since the extract under subcritical conditions only contained the essential oil, we posited that a clear separation of the essential oil and the oleoresin could be possible by operating a dual mode extraction. In this scheme, the first mode would be operated under subcritical conditions, after which the temperature and pressure would be increased to the preferred supercritical conditions. Figure 4 shows the extraction curve obtained by initially operating at $25^{\circ} \mathrm{C}$ and 65 bar pressure for 1 hour and then operating at 50 bar and 350 bar pressure. The subcritical and supercritical portions of the curve are clearly identified; the yield under subcritical conditions asymptotes at approximately $5 \%$. Essential oil component compositions were measured for the duration of the experiments to examine the 
potential for essential oil/oleoresin separation by this approach; these results are shown in Figure 5. Although there is a reduction in the essential oil components toward the end of the subcritical extraction phase, once the supercritical conditions are introduced, the major components (turmerone, ar-tumerone, and beta-sesquiphellandrene) are extracted at a higher rate, which is maintained until the end of the extraction.

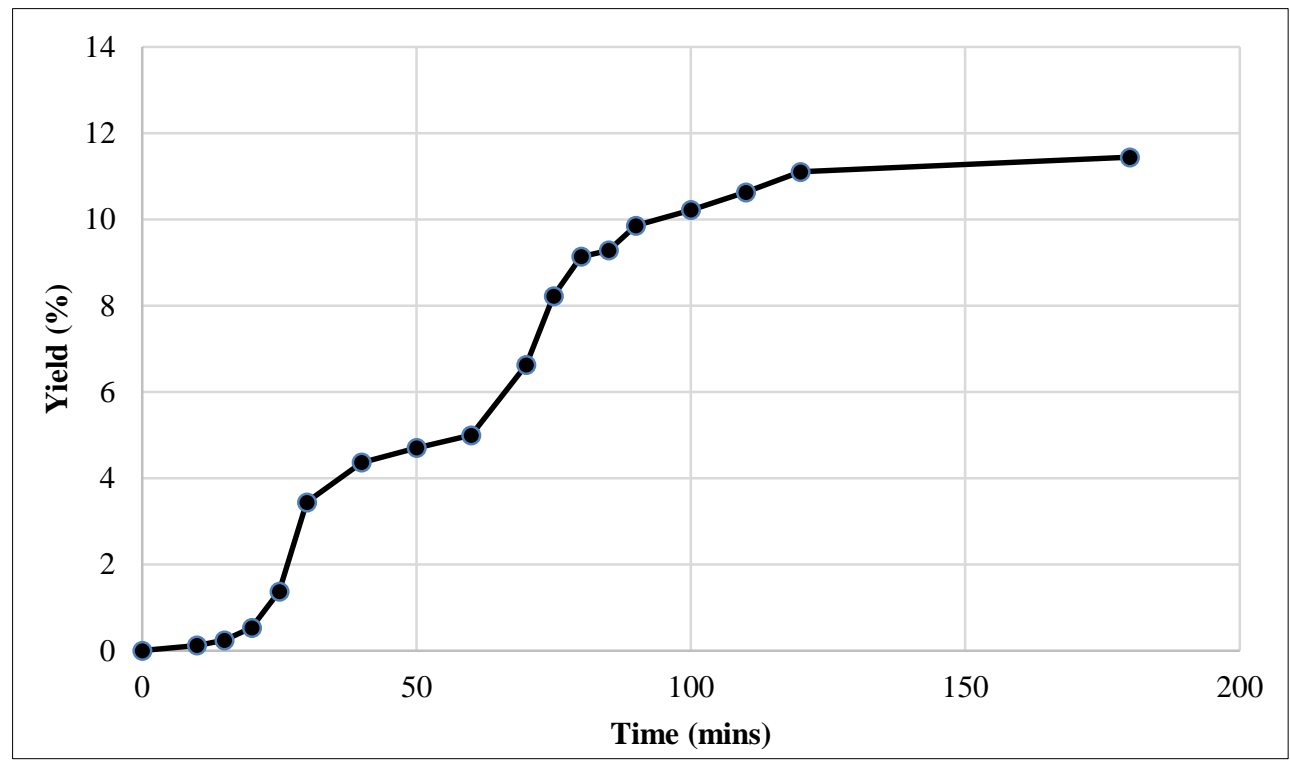

Figure 4. Combined extraction curve: 60 mins at $25{ }^{\circ} \mathrm{C}$ and 65 bar, followed by a temperature of $50{ }^{\circ} \mathrm{C}$ and a pressure of 350 bar

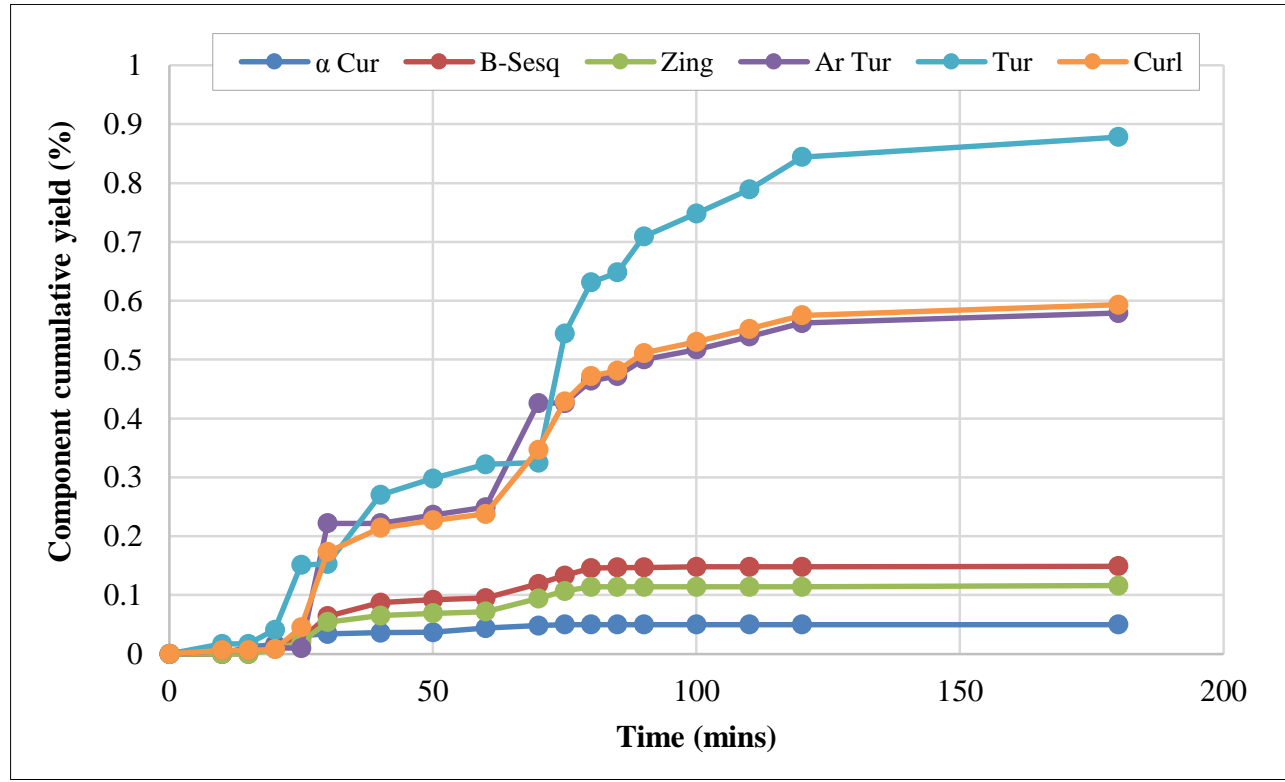

Figure 5. Extraction of essential oil components with time during combined mode extraction

\section{Discussion}

\subsection{Implications of the Experimental Results}

The differences in raw materials obtained from harvesting at four months after planting and eight months after planting were negligible, and therefore allow for flexibility in raw material supply for commercial production. Both oven drying and freeze drying produced satisfactory results; however, oven drying is preferred because it is more suitable to the continuous drying of large amounts of raw material. The experimental results indicate that only essential oil is extracted under subcritical conditions. Operating under supercritical conditions will give a combined extract. Combined extraction produces an essential oil under subcritical conditions, but the subsequent supercritical extraction contains a mixed extract. The most appropriate approach to a commercial process is therefore to operate under combined mode beginning with subcritical extraction at $25^{\circ} \mathrm{C}$ and 65 bar for 60 minutes followed by supercritical extraction at $50{ }^{\circ} \mathrm{C}$ and 350 bar pressure for a further 120 minutes. Since these experiments were carried out using a small-scale laboratory extractor and commercial scale extractors will be much larger, a conservative overall yield of $7 \%$ is chosen for the overall extraction. 


\subsection{Commercialization Based on Laboratory-scale Experimentation}

\section{Financial Analysis}

A structured reintroduction of the plant extracts industry to Trinidad and Tobago would ultimately lead to the downstream development, production, and marketing of value-added consumer products from the extracted oils and oleoresins. A new, financially viable business venture based on turmeric extraction would assist in the resuscitation of the agriculture industry in Trinidad and Tobago, particularly if developed on unused/underutilized agricultural land. The resulting products could be expected to stimulate local employment (particularly if farmers are contracted to supply the raw materials) and would attract much needed foreign exchange.

The success of the enterprise would depend on ensuring a supply of crops with high oil content, carefully managing the delivery of raw materials to the process plant, minimizing operation costs, and efficient marketing, which would all enable the business to respond to market demands and price fluctuations. The twin-island state of Trinidad and Tobago already has some local experience in the industry, including trained and semi-skilled manpower for both agricultural production and process plant operation. There is also significant underutilized land that would be suitable for growing the turmeric crop. The low cost of utilities and the availability of carbon dioxide as a waste product from ammonia plants in Trinidad would assist in keeping operation costs low. Furthermore, established expertise in extraction technology and oil analysis at local universities would also provide the necessary research support to develop the extraction industry.

While an alternative approach to raw material supply would entail renting/purchasing land to produce the crop for delivery to the plant, in the following financial analysis, it is assumed that contracted farmers will produce the turmeric crop and deliver these materials to the plant site as required. The company's focus would then be the operation of the process plant, as well as the sales and distribution of the extracted essential oils. It would be strategically prudent to site the plant close to the raw material supply to minimize transportation costs and the carbon footprint of the operation. The use of mechanized agriculture systems could also reduce the cost of the raw materials for the process. We suggest that an initial strategy that focuses on marketing through established brokers in North America and Europe, but as the business matures, a strategy involving direct sales to manufacturers of consumer products would be appropriate. In the long-term, the focus of the enterprise could shift to refining the extracted oils on site, which would enable the production of consumer products for direct distribution and the initiation of a national consumer products industry based on the oils produced.

\section{Operations}

Two distinct and separate operations are involved: the provision of raw materials for processing, and the extraction of the oils from the crops. It is assumed that the raw material will be supplied to the processing site by contracted farmers at a price of US $\$ 1.00$ per kg of turmeric. After drying and milling, the raw materials will be charged to the processing unit where the oils will be extracted. A diagram of the SFE process is shown in Figure 6. In this batch process, the raw material is charged into a basket close to the extraction vessel and when it is full, the basket is hoisted up and deposited on a perforated grid at the base of the vessel. The top lid is then closed and clamped after which carbon dioxide at high pressure is passed to the underside of the grid. Subsequently, the carbon dioxide passes through the plant material and uptakes the extracted oils from the material. The production of oils is highest at the beginning of the run but as the oil content of the plant material reduces with time, the oil production rate also reduces until the material is exhausted.

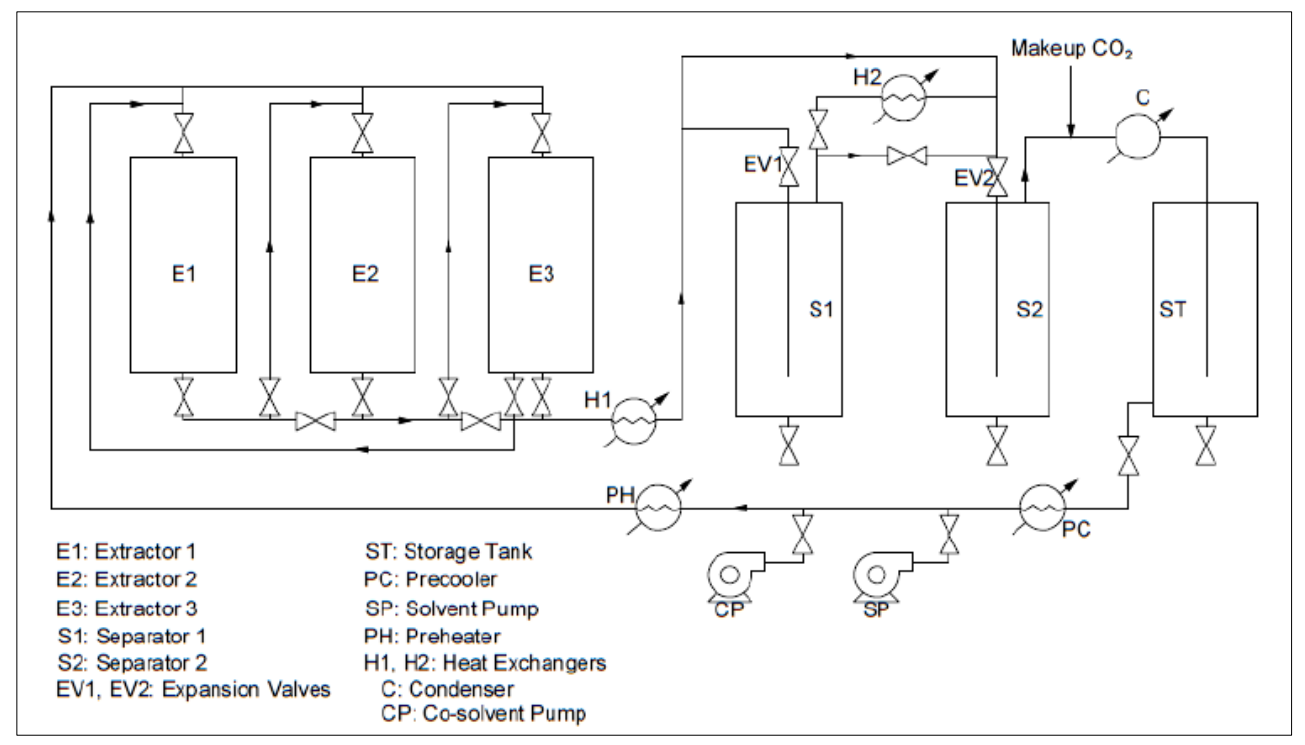

Figure 6. A semi-continuous SFE process 
When the rate of production drops to a low level, the flow of carbon dioxide is stopped. The top lid is then opened, and the basket is removed. The spent material is removed from the basket and a new charge is introduced. The process is then repeated. Figure 6 shows a system that would be suitable for commercial use, with three extractors at a capacity of 1,500 liters. The experimental program (detailed in Section 3) has shown that the bulk of the extraction takes place in the first two hours. Since the production units are 1,500 times the size of the laboratory unit, an extraction time of three hours is initially projected for production. A turnaround time of just under two hours is assumed, which should be adequate for emptying and refilling the units. It should also allow for the completion of small maintenance jobs within the production schedule. Thus, for a 24-hour, 7-day operation there would be five batches per unit per day for each of the three units; this totals to 15 batches per day for the total operation. Bulk density tests have indicated that the batch charge should have a bulk density of approximately 300 grams per liter. Each batch charge would therefore be $1,500 \times 0.3$ $=450 \mathrm{~kg}$. However, the in-vessel bulk density of the raw material is likely to be higher than 300 grams per liter in the full-scale plant, so a batch size of 0.5 tonnes is used in the analyses. This should be verified at start up. The annual raw material requirement for the process plant for a 300-day operation is therefore: 15 (batches per day) $\times 0.5$ (batch charge - dried) $\times 300$ (days per year) $=2,250$ tonnes.

It is likely that the turmeric will be supplied to the processing site at approximately $60 \%$ wet basis moisture. This needs to be dried to approximately $15 \%$ wet basis moisture. This means that farmers will have to supply approximately 4,800 tonnes per year. It is proposed that the spent material should be composted, and the compost produced could be utilized for agricultural production or an additional revenue stream on the local market.

\section{Capital Expenditure}

The major item requiring capital expenditure is the process plant. We propose a packaged system with three extraction vessels and two separators as shown in Figure 6. The carbon dioxide will be recycled to minimize carbon dioxide use. The cheapest quote obtained gave an estimated price of a system comprising $3 \times 1,500 \mathrm{~L}$ vessels with an operating pressure of up to 350 bar of US\$2.6 million, excluding delivery. We assume a value of US\$3 million in this financial analysis to allow for delivery and other contingencies. The other capital expenditure items relate to the receipt and preparation of the raw material, process buildings (including a small analytical laboratory), office buildings, services, and various indirect costs associated with the development of the site. The expected capital cost expenditure is estimated to be US\$4,500,000.

\section{Operating Cost}

The largest operating cost will be the supply of raw materials to the factory gate. As previously discussed, the annual supply of 4,800 tonnes of raw materials the plant is projected to be purchased at US\$1 per $\mathrm{kg}$. The annual cost of the raw material supply is therefore estimated to be US\$4,800.000. Manpower costs for operating the plant, office administration, sales and security are estimated at approximately US $\$ 420,000$ annually at the prevailing local rates. Other operating costs, such as utilities, rent, marketing and distribution, as well as general supplies, bring the estimated annual operating cost to US\$5,600,000.

\section{Revenue}

The raw material supply (4,800 tonnes per year) will have to be dried to $<15 \%$ wet basis before charging to the extraction process. As discussed previously in Section 4.2.2, approximately 2,250 tonnes per year will be charged to the process, producing 134,400 tonnes of oil at the conservative $6 \%$ yield (as determined from the experimental program). Annual revenues are therefore expected to be US\$ 6,750,000 at the projected selling rate of US\$50 per kg of oil.

\section{Return on Investment}

The revenue and cost projections detailed in the prior sections are the best estimates based on available data as of 2020. Financial feasibility was evaluated for a period of 10 years at a discount rate of $10 \%$. This showed an internal rate of return (IRR) of $19 \%$ with a net present value (NPV) of US\$1.878 million. It may therefore be concluded that the project is financially viable with an acceptable potential return and is worthy of future development. However, it is appropriate to further investigate some of the assumed figures in the form of a sensitivity analysis, which evaluates the effects of potential changes in capital costs, raw material costs, oil yields, throughput variation, and product prices. Only one of these variables is changed at a time in these determinations. The sensitivity analysis provides a useful understanding of the effects of the various system variables in the refining of the cost estimates, which will aid investment decisions. The results are detailed below in Table 1.

It can be inferred from Table 1 that the expected return on the initial investment is not very sensitive to capital cost overruns but is quite sensitive to the price of raw materials, oil yield, plant utilization, and product prices. The project ceases to be profitable if the raw material cost exceeds US $\$ 1.10$ per $\mathrm{kg}$, the yields fall below $6.5 \%$, the plant utilization falls below $75 \%$, or the selling price is below US\$47. Substantial profits are realized if the selling price exceeds US\$55. 
Table 1. A sensitivity analysis; all prices are in US dollars

\begin{tabular}{|c|c|c|c|}
\hline Variable & New Quantum & IRR & NPV \\
\hline \multirow{3}{*}{ Capital Expenditure } & $\$ 5.0$ million & $16 \%$ & $\$ 1.424$ million \\
\hline & $\$ 5.5$ million & $14 \%$ & $\$ 0.969$ million \\
\hline & $\$ 6.0$ million & $12 \%$ & $\$ 0.515$ million \\
\hline \multirow{4}{*}{ Raw Material Price } & $\$ 0.95$ per $\mathrm{kg}$ & $25 \%$ & $\$ 3.219$ million \\
\hline & $\$ 1.05$ per kg & $13 \%$ & $\$ 0.538$ million \\
\hline & $\$ 1.10$ per $\mathrm{kg}$ & $6 \%$ & $-\$ 0.803$ million \\
\hline & $\$ 1.15$ per $\mathrm{kg}$ & $-3 \%$ & $-\$ 2.143$ million \\
\hline \multirow{4}{*}{ Oil Yields } & $5.0 \%$ & $-35 \%$ & -\$4.406 million \\
\hline & $5.5 \%$ & $3 \%$ & $-\$ 1.264$ million \\
\hline & $6.5 \%$ & $32 \%$ & $\$ 5.021$ million \\
\hline & $7.0 \%$ & $44 \%$ & $\$ 8.163$ million \\
\hline \multirow{4}{*}{ Plant Utilization } & $90 \%$ & $23 \%$ & $\$ 2.913$ million \\
\hline & $80 \%$ & $18 \%$ & $\$ 1.590$ million \\
\hline & $70 \%$ & $11 \%$ & $\$ 0.263$ million \\
\hline & $60 \%$ & $4 \%$ & $-\$ 1.063$ million \\
\hline \multirow{4}{*}{ Product Prices } & $\$ 44$ per kg & $-6 \%$ & $-\$ 2.646$ million \\
\hline & $\$ 47$ per kg & $8 \%$ & -\$0.384 million \\
\hline & $\$ 53$ per $\mathrm{kg}$ & $29 \%$ & $\$ 4.141$ million \\
\hline & $\$ 57$ per $\mathrm{kg}$ & $41 \%$ & $\$ 7.157$ million \\
\hline
\end{tabular}

\section{Conclusion}

The approach used here is extensible to the evaluation of other extraction projects in other small countries (such as Caribbean countries). It may be concluded that the project is technically feasible, and the initial financial analysis suggests that it is also financially feasible; however, the caveats highlighted by the sensitivity analysis must be considered. In particular, the implications for the supply to the process plant should be carefully reviewed and the factory gate delivery price per kg should be confirmed. It would also be useful to confirm the extraction data for the preferred conditions with a larger extraction unit (e.g., a 5-liter unit). A market survey should be carried out to assess the potential for selling all oil produced at the projected price (US\$55) or better. Samples of the extract should then be sent to brokers for assessment. The capital cost data should be reassessed based on quotes from additional suppliers and contractors. Finally, the economic feasibility study should then be modified accordingly, considering the updated information provided by additional quotes, secured pricing, and alternative system configurations.

\section{Declarations}

\subsection{Author Contributions}

Conceptualization, R.S. and D.R.M.; methodology, R.S.; validation, S.M. and D.R.M.; formal analysis, R.S., S.M., and D.R.M.; investigation, R.S.; data curation, R.S.; writing — original draft preparation, R.S., S.M., and D.R.M.; writing - review, editing, D.F.; visualization, D.F. and S.M.; supervision, D.R.M.; project administration, S.M. and D.R.M.; funding acquisition, R.S. All authors have read and agreed to the published version of the manuscript.

\subsection{Data Availability Statement}

The data presented in this study are openly available in doi:10.17632/fwdrzffcdb.2.

\subsection{Funding}

The authors received no financial support for the research, authorship, and/or publication of this article.

\subsection{Acknowledgements}

The authors wish to thank the research assistant and laboratory maintenance staff of the Department of Chemical Engineering at the University of the West Indies, St Augustine Campus (Trinidad and Tobago) for their support. 


\subsection{Institutional Review Board Statement}

Not applicable.

\subsection{Informed Consent Statement}

Not applicable.

\subsection{Declaration of Competing Interest}

The authors declare that there is no conflict of interests regarding the publication of this manuscript. In addition, the ethical issues, including plagiarism, informed consent, misconduct, data fabrication and/or falsification, double publication and/or submission, and redundancies have been completely observed by the authors.

\section{References}

[1] King, K. (2006). Packaging and storage of herbs and spices. In Handbook of Herbs and Spices, 3, 86-102. Food Science, Technology and Nutrition. doi:10.1533/9781845691717.1.86.

[2] Ríos, J. L. (2016). Essential oils: What they are and how the terms are used and defined. In V.R. (Ed.), Essential Oils in Food Preservation, Flavor and Safety (pp. 3-10). San Diego. doi:10.1016/B978-0-12-416641-7.00001-8.

[3] Turek, C., \& Stintzing, F. C. (2013). Stability of essential oils: A review. Comprehensive Reviews in Food Science and Food Safety, 12(1), 40-53. doi:10.1111/1541-4337.12006.

[4] Moyler, D. A. (1991). Oleoresins, tinctures and extracts. In F. Flavourings \& P. R. Ashurst (Eds.), Food Flavourings. Springer US. doi:10.1007/978-1-4613-0499-9_3.

[5] Allied Market Research (2021). Essential Oils Market Expected to Reach \$15,618.8 Million by 2026. Available online: https://www.alliedmarketresearch.com/press-release/essential-oils-market.html (accessed on May 2021).

[6] Fortune Business Insights (2021). Essential Oils Market Size, Share and Industry Analysis by Type (Citrus, Eucalyptus, Lavender, Rosemary, Tea Tree, and Others), Application (Food \& Beverages, Personal Care \& Cosmetics, Pharmaceuticals, and Others), and Regional Forecast 2019-2026. Available online: https://www.fortunebusinessinsights.com/industry-reports/essential-oilsmarket-101063 (accessed on March 2021).

[7] Global Market Insights Inc. (2021). Essential Oils Market Size By Application (Orange oil, Lemon oil, Eucalyptus oil, Clove oil, Peppermint oil, Jasmine oil, Rosemary oil, Cornmint oil, Citronella oil, Geranium, Spearmint oil, Lavender oil, Tea tree oil and others), By Application (Food \& beverage, Aromatherapy, Cosmetics \& Toiletries, Pharmaceuticals, Cleaning \& Home care, Animal Feed, Fragrances and Others) Industry Analysis Report, Regional Outlook, Growth Potential, Competitive Market Share \& Forecast, 2019-2026. Available online: https://www.gminsights.com/industry-analysis/essential-oil-market (accessed on March 2021).

[8] Grand View Research (2021). Essential Oils Market Demand To Reach 473.31 Kilotons By 2027. Available online: https://www.grandviewresearch.com/press-release/globalessential-oil-market, 2020. (accessed on March 2021).

[9] Oleoresins Market by Source (2021). (Paprika, Capsicum, Seed spices, Turmeric, Herbs, Ginger, Cinnamon \& Cassia), Application (Food \& Beverages, Pharmaceutical \& Nutraceutical, Personal Care Products, Feed), Extraction Process, and Region - Global Forecast to 2025. Available online: https://www.marketsandmarkets.com/Market-Reports/oleoresins-market-50554584.html (accessed on March 2021).

[10] Dominica Essential Oils \& Spices Co-operatives Society (2021). History on the Dominica Essential Oils \& Spices Co-operative Limited (DEOCS). Available online: http://cooperative.gov.dm/featured/30-essentialoils (accessed on March 2021).

[11] Gayle, J. (2013). PimentoThe Jamaica allspice story (No. 633.83729. 2). Inter-American Institute for Cooperation on Agriculture (IICA), Costa Rica.

[12] Ewing-Chow, Daphne. Nutmeg: Grenada's 'Black Gold' is On the Cusp of Resurgence. Available online: https:// forbes.com/sites/daphneewingchow/2020/02/23/nutmeg-grenadas-black-gold-is-on-the-cusp-of-resurgence/?sh=e0af2c33f28a, (accessed on March 2021).

[13] Persad, R. (1998). Steam Distillation of the Essential Oil of Anise (Pimpinella anisum). Thesis, University of the West Indies, St. Augustine, Trinidad and Tobago.

[14] New agriculturist (2021). Essential Extracts: Caribbean elixir. Available online: http://www.new-ag.info/en/002/focuson/focuson6.html (accessed on March 2021).

[15] Watson, M. (2005). Supercritical Fluid Extraction of Ylang Ylang. Thesis, University of the West Indies, St. Augustine, Trinidad and Tobago.

[16] Paltoo V. (2002). Supercritical Fluid Extraction of Jasmine and other Flavour and Fragrance Materials. Ph.D. thesis, University of the West Indies, St Augustine, Trinidad and Tobago. 
[17] Tompsett, G. A., Boock, J. T., DiSpirito, C., Stolz, E., Knutson, D. R., Rivard, A. G., ... \& Timko, M. T. (2018). Extraction rate and energy efficiency of supercritical carbon dioxide recovery of higher alcohols from dilute aqueous solution. Energy Technology, 6(4), 683-693. doi:10.1002/ente.201700626.

[18] Maharaj S. (2011). Extraction Studies with Basil. Ph.D. thesis, University of the West Indies, St Augustine, Trinidad and Tobago.

[19] Das, K. (2016). Turmeric (Curcuma longa) oils. In V.R. (Ed.), Essential Oils in Food Preservation, Flavor and Safety (pp. 835841). San Diego. doi:10.1016/B978-0-12-416641-7.00095-X.

[20] Prasath, D., Kandiannan, K., Leela, N. K., Aarthi, S., Sasikumar, B., \& Babu, K. N. (2018). Turmeric: Botany and production practices. Horticultural Reviews, Volume 46, 99-184. doi:10.1002/9781119521082.ch3.

[21] Mahady, G. B., Pendland, S. L., Yun, G., \& Lu, Z. Z. (2002). Turmeric (Curcuma longa) and curcumin inhibit the growth of Helicobacter pylori, a group 1 carcinogen. Anticancer Research, 22(6 C), 4179-4181.

[22] Haroyan, A., Mukuchyan, V., Mkrtchyan, N., Minasyan, N., Gasparyan, S., Sargsyan, A., Narimanyan, M., \& Hovhannisyan, A. (2018). Efficacy and safety of curcumin and its combination with boswellic acid in osteoarthritis: A comparative, randomized, double-blind, placebo-controlled study. BMC Complementary and Alternative Medicine, 18(1), 1-16. doi:10.1186/s12906-0172062-z.

[23] Guenther, E., \& Althausen, D. (1948). The essential oils. Lancaster Press, New York, USA.

[24] Lawrence, B. M. (1995). The isolation of aromatic materials from natural plant products. In K. Silva (Ed.), K. Tuley de Silva (ed.). A manual on the essential oil industry. Proceedings of the 3rd UNIDO Workshop on Essential Oil and Aroma Chemical Industries (pp. 57-154). Vienna, Austria.

[25] Demissew, S., \& Asfaw, N. (1998). Essential Oil Crops. In Economic Botany, 52(4). CAB International. doi:10.1007/bf02862070

[26] Brunner, G. (1994). Gas Extraction: An Introduction to Fundamentals of Supercritical Fluids and the Application to Separation Process 1 Ed. (p. 387), Steinkopff-Verlag Heidelberg, Berlin, Germany.

[27] Lee, W.-J., Suleiman, N., Hadzir, N. H. N., \& Chong, G.-H. (2020). Supercritical fluids for the extraction of oleoresins and plant phenolics. Green Sustainable Process for Chemical and Environmental Engineering and Science, 279-328. doi:10.1016/b9780-12-817388-6.00012-x.

[28] Mukhopadhyay, M. (2000). Natural extracts using supercritical carbon dioxide. In Natural Extracts Using Supercritical Carbon Dioxide. CRC Press, Florida, United States. doi:10.1201/9781420041699. 